\title{
Determinants of assault-related violence in the community: potential for public health interventions in hospitals
}

\author{
S E Ramsay, ${ }^{1}$ A Bartley, ${ }^{2}$ A J Rodger ${ }^{3}$
}

${ }^{1}$ Research Department of Primary Care and Population Health, University College London, London, UK ${ }^{2}$ Department of Public Health, Royal Free Hospital, London, UK

${ }^{3}$ Research Department of Infection and Population Health, University College London, London, UK

Correspondence to Dr Sheena E Ramsay, Research Department of Primary Care and Population Health, University College London (UCL), Royal Free Campus, Rowland Hill Street, London NW3 2PF, UK;

s.ramsay@ucl.ac.uk

Received 11 June 2013 Revised 24 July 2013 Accepted 25 July 2013
To cite: Ramsay SE, Bartley A, Rodger AJ. Emerg Med I Published Online First: [please include Day Month Year] doi:10.1136/ emermed-2013-202935

\begin{abstract}
Background Data from emergency departments (EDs) in England describe the epidemiology of violent assaults. However, the potential of such data to inform hospitalbased public health interventions remains unknown. Objective To identify determinants of assaults using ED data to inform development of programmes delivered in acute Trusts for reducing assault-related injuries in the community.

Methods Data were collected from a large North London acute Trust on assault-related injuries reporting to A\&E over 18 months (July 2010-February 2012). Information was recorded on patient demographics and assaults (place of assault, type of assault, relation to assailant) through questionnaires administered by ED reception staff.

Results 1210 assaults were recorded between July 2010 and February 2012. 18\% of assaults were severe (strangling, stabbings, sexual assaults). $75 \%$ of assault victims were men, $37 \%$ were young adults (2030 years) and $15 \%$ were teenagers. A higher proportion of victims lived in more deprived areas. Apart from public streets $(48 \%)$, the main location of assaults was at home (20\%). Female compared with male victims were significantly more likely to be both assaulted at home (OR 6.13; 95\% Cl 4.41 to 8.54 ) and to be assaulted by a known assailant (family member, friend, partner/ex-partner; OR 8.20, 95\% CI 5.85 to 11.48).

Conclusions The results highlight the notable contribution of domestic violence to assaults presenting to hospital ED. Such findings can be used to plan interventions such as screening hospital patients for domestic violence. ED data have the potential to inform hospital-based initiatives to address issues such as assaults in the local population.
\end{abstract}

\section{INTRODUCTION}

Violence and physical abuse have a significant impact on the health and well-being of individuals. The Crime Survey for England and Wales in 201112 reported 2.1 million violent incidents with 3\% adults affected. ${ }^{1}$ Apart from immediate consequences such as physical injuries, violence impacts on a range of short-term and long-term outcomes such as antisocial behaviour, emotional and mental health problems (particularly in children) and sexually transmitted diseases. ${ }^{2}{ }^{3}$ Almost half of all violence-related crimes are reported to be alcoholrelated. ${ }^{1}$ Domestic violence also contributes significantly to assault-related injuries with the Crime Survey for England and Wales in 2011-12 reporting that $7 \%$ of women and $5 \%$ of men were estimated to have experienced some form of domestic abuse over the year (equivalent to an estimated 1.2 million female and 800000 male victims). ${ }^{1}$ Reducing violent crimes and physical abuse forms an important part of ensuring a safe living environment and the Department of Health publication Healthier, Fairer, and Safer Communities (2008) provides a framework for a joined up approach to address the root causes of violence focusing on early prevention and addressing factors that increase the risk of violence in populations. ${ }^{2}$

Evidence has shown that hospitals can contribute effectively to violence prevention by working in partnership with local crime and disorder reduction partnerships. ${ }^{4-6}$ Studies have shown that assaults reporting to emergency departments (EDs) are under-reported to the police. ${ }^{7-9}$ Initiatives in England and Wales to share anonymised data on assaults (eg, the location of violent incidents) have helped police target 'hot spot' areas resulting in reduced violence and related attendances by about $30 \%$ in EDs in Cardiff, Cambridge and Wirral area in North West England; ${ }^{4-6}$ the effectiveness of one such initiative has also been reported. ${ }^{5}$ The Coalition Commitment Programme was launched by the Department of Health to enable sharing of information between hospitals and the local police to reduce violence-related health and social consequences. ${ }^{10}$ The College of Emergency Medicine has also published guidance on the collection of violence-related data in hospital EDs. ${ }^{11}$ Nevertheless, the potential of such data to inform development of hospital-based strategies to reduce violence in the local population remains unknown. In this study, we aimed to identify determinants of violence/assaults attending the ED of a large acute hospital in London to inform hospitalbased prevention strategies to address the issue of violent assaults in the local population.

\section{METHODS}

The Royal Free Hospital is a large acute hospital in North London with a catchment area that serves the population of six north London boroughs (Barnet, Camden, Islington, Haringey, west Enfield and east Brent). The ED provides emergency medical service $24 \mathrm{~h}$ a day. A total of 93285 attendances were reported in the ED between 2012 and 2013.

In an effort to reduce alcohol-related violence in the local community, the Royal Free Hospital was asked to work in conjunction with the local Community Safety Partnership which are statutory bodies comprising the local Council, the local police and police authority and the Government Office for London to collect data on assaults 
attending the accident and emergency (A\&E) department. Our data sharing model was based on that implemented in 2009 in Cardiff ${ }^{12}$ to collect information on assault-related injuries presenting to the hospital ED. At the time of reporting to the ED, individuals with an assault injury were identified by ED reception staff through an initial enquiry and were asked to complete a self-administered paper-based questionnaire (for those under 18 years, the questionnaire was completed, where possible by the parent/guardian). The questionnaire recorded demographic details of the victim, nature of the assault, location of the assault, demographic details of assailants and the victim's relationship to assailants. It was also possible through this model to identify repeat attenders at ED. No patient identifiable information was collected in the questionnaire and all data were used in non-identifiable format to maintain confidentiality throughout. We used these data routinely collected in the ED for the analyses. Ethical approval for data analysis and publication was obtained from the research ethics committee (reference 12/SC/ 0377).

Victims were asked in the questionnaire if they had consumed alcohol prior to the assault and this was used as a proxy measure of alcohol-related assaults. Socioeconomic deprivation was based on the Index of Multiple Deprivation (IMD) 2010 score at lower super output area (LSOA) level for the victims as determined by their postcode of residence. This was obtained from the Department for Communities and Local Government website (http://www.communities.gov.uk). LSOAs are geographical areas with an average population size of 1500 individuals. The national IMD ranks were divided into quintiles and applied to the LSOAs for participants in the analysis.

Statistical analyses: We first examined descriptive/demographic characteristics of the study population presented as proportions. To estimate relative risks, prevalence ratios and 95\% CIs were calculated for locations of assault and relation to assailants according to gender (female victims as the reference group). Gender was fitted as a categorical variable. All analyses were carried out using SAS statistical software V.9.2.

\section{RESULTS}

Overall, 1210 assaults were recorded through this initiative in A\&E between July 2010 and February 2012. This represents a $74 \%$ response rate (a total of 1632 patients were recorded in the Hospital ED's dataset with 'assault' recorded in the presenting complaint or diagnosis fields). Most victims $(75 \%, \mathrm{n}=905)$ presented to the ED within $24 \mathrm{~h}$ of the assault. Table 1 documents the different types of assaults; 19\% were severe including strangling, stabbing, sexual assaults, victim pushed through door/ window, and assaults with glass/bottle or firearms/explosives. Overall, $48 \%$ of assaults were carried out by two or more

Table 1 Type of assaults reported

\begin{tabular}{lc}
\hline Punched/pushed/slapped/kicked/blunt object & $869(75 \%)$ \\
Strangled & $42(4 \%)$ \\
Bitten & $11(1 \%)$ \\
Glass/bottle injury & $98(8 \%)$ \\
Knife/bladed object & $47(4 \%)$ \\
Pushed through door/window & $7(0.6 \%)$ \\
Firearms/explosives & $3(0.3 \%)$ \\
Sexual assault & $13(1 \%)$ \\
Other & $76(7 \%)$ \\
Total (missing $\mathrm{n}=44)$ & $1166(100 \%)$ \\
\hline
\end{tabular}

assailants. The assailants were mostly male (86\%) and 19\% were aged less than 20 years. Of the total assaults, 3\% $(n=41)$ were repeat assaults within this study period on the same victim.

Table 2 presents sociodemographic characteristics of the victims of assaults. Most victims were male (75\%). The highest proportion were young adults aged 20-29 years (38\%) followed by those aged $30-39$ years $(22 \%) ; 15 \%$ of victims were teenagers (15-19 years). In all, 53\% were of white British or white other ethnicity (the estimated proportion of white ethnic groups in the catchment area of the hospital is $63 \%$ based on 2011 Greater London Authority population estimates). Based on IMD quintiles, only $4 \%$ of victims came from the least deprived area while $64 \%$ lived in the most deprived areas.

Over half $(55 \%, 474 / 866)$ of the victims reported that they have consumed alcohol before the assault. A higher proportion of male (59\%) compared with female victims (41\%) reported alcohol-related assaults. Victims aged 20-59 years reported a higher proportion of alcohol-related assaults compared with those aged 15-19 years (figure 1).

Most assaults were reported to have taken place on the street (48\%) while $20 \%$ took place at home (either the victim's or assailant's) (table 3). Female compared with male victims were more likely to be assaulted at home (44\% compared with 12\%, prevalence ratio $3.79 ; 95 \%$ CI 2.99 to $4.80 ; \mathrm{p}=<0.0001$ ). Female victims were less likely to be assaulted in bars/clubs and on the street compared with men.

Table 2 Demographic characteristics of assault victims reported during an 18-month period

\begin{tabular}{|c|c|}
\hline \multicolumn{2}{|l|}{ Gender } \\
\hline Male & $857(75 \%)$ \\
\hline Female & $282(25 \%)$ \\
\hline Total (missing $n=71$ ) & $1139(100 \%)$ \\
\hline \multicolumn{2}{|l|}{ Age groups } \\
\hline $0-14$ & $28(2.5 \%)$ \\
\hline $15-19$ & $176(15 \%)$ \\
\hline $20-29$ & $433(38 \%)$ \\
\hline $30-39$ & $249(22 \%)$ \\
\hline $40-59$ & $211(19 \%)$ \\
\hline $60+$ & $43(4 \%)$ \\
\hline Total (missing $n=70$ ) & $1140(100 \%)$ \\
\hline \multicolumn{2}{|l|}{ Ethnicity } \\
\hline White British Irish & $426(35 \%)$ \\
\hline White Other & $217(18 \%)$ \\
\hline Asian or Asian British & $128(11 \%)$ \\
\hline Black/Black British Caribbean Other & $112(9 \%)$ \\
\hline Mixed Other & $16(1 \%)$ \\
\hline Mixed White Black Caribbean & $9(0.7 \%)$ \\
\hline Chinese & $5(0.4 \%)$ \\
\hline Mixed White Asian & $4(0.3 \%)$ \\
\hline Not known & $182(15 \%)$ \\
\hline Other ethnic group & $111(9 \%)$ \\
\hline Total & $1210(100 \%)$ \\
\hline \multicolumn{2}{|c|}{ Socioeconomic deprivation-Index of Multiple Deprivation quintiles } \\
\hline 1 (least deprived) & $40(4 \%)$ \\
\hline 2 & $146(14 \%)$ \\
\hline 3 & $208(19 \%)$ \\
\hline 4 & $351(33 \%)$ \\
\hline 5 (most deprived) & $330(31 \%)$ \\
\hline Total (missing $n=135$ ) & $1075(100 \%)$ \\
\hline
\end{tabular}


Figure 1 Alcohol-related assaults according to age groups of victims.

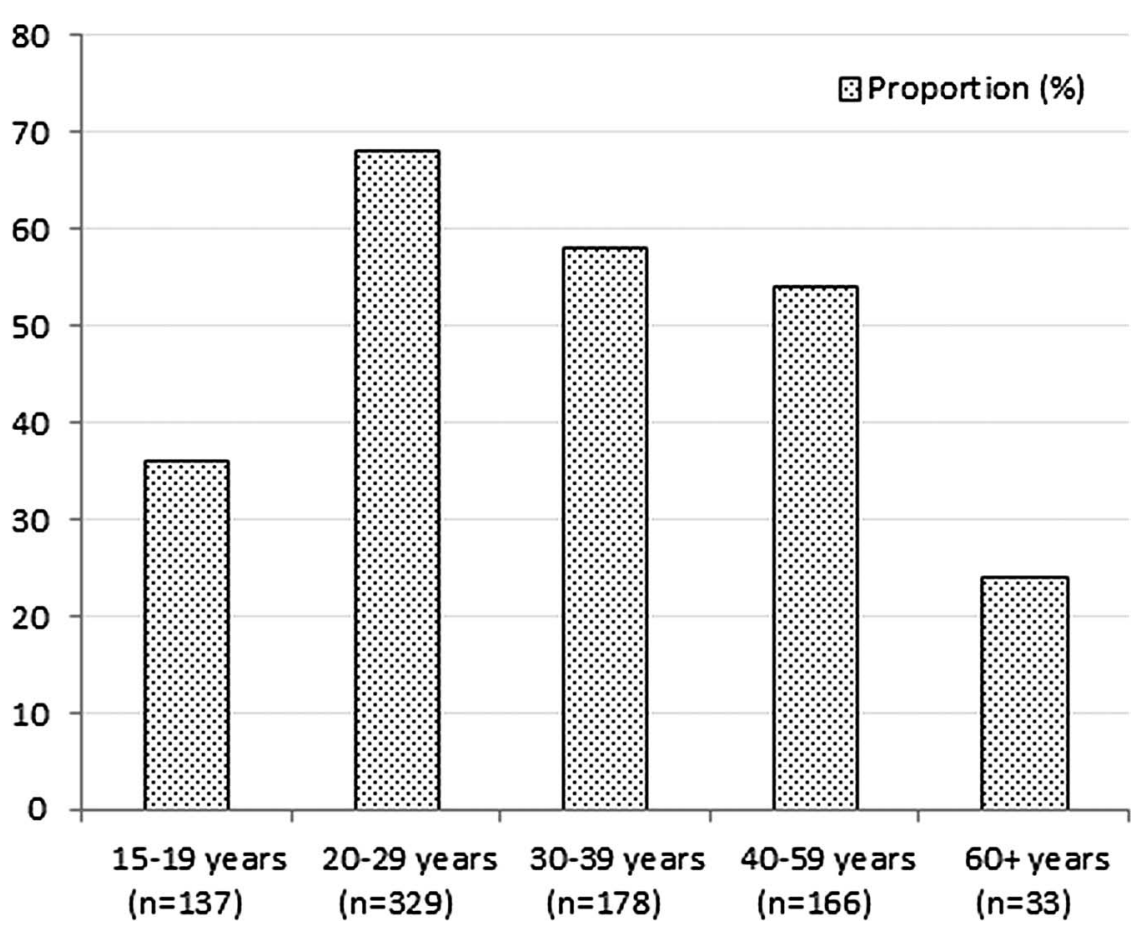

Table 3 also shows the relationship of the assailant to the victim and the distribution according to gender. Overall, 21\% of victims were assaulted by a known assailant (family member, partner/ex-partner or friend). Female compared with male victims were more likely to be assaulted by a known assailant (prevalence ratio 4.34 ; 95\% CI 3.45 to 5.48 ; $\mathrm{p}=<0.0001$ ) and were less likely to be assaulted by a stranger (table 3 ). In all, $9 \%$ of victims $(n=71)$ reported to having ever been previously assaulted by the same assailant. A greater proportion of female compared with male victims reported a previous assault by the same assailant $(28 \%(n=48)$ women compared with $4 \%(n=21)$ men, $\mathrm{p}$ value $=<0.0001)$.

\section{DISCUSSION}

The specific purpose of this study was to identify determinants of assaults reported in a hospital ED, which could then be used to inform hospital-based public health initiatives to address assaults in the local population. We demonstrated through a review of these data the notable contribution of domestic violence towards women to overall assault. We found that a fifth of assaults occurred at home and that women were significantly more likely than men to be assaulted in their own home. Women were also four times more likely to be assaulted by a known assailant (family member, partner/ex-partner) than men. These findings of domestic violence led to inform the planning of an initiative for domestic violence screening in the hospital.

We also found that overall, three-quarters of victims were male, over half were of white ethnicity and that victims were more likely to live in economically deprived areas. The highest proportion of victims overall were young adults aged 2029 years. We also found that over half of victims reported to have consumed alcohol before the assault, and that men were more likely to have alcohol-related assaults compared with women. This epidemiology of assaults in our population

Table 3 Location of assault and relation of victim to assailant by gender

\begin{tabular}{|c|c|c|c|c|}
\hline & All (\%) & Female (\%) & Male (\%) & Prevalence ratio $(95 \% \mathrm{Cl})$ female to male victims \\
\hline \multicolumn{5}{|l|}{ Location of assault } \\
\hline Home (victim's/assailant's) & $218(20)$ & $119(44)$ & $90(12)$ & 3.79 (2.99 to 4.80$)$ \\
\hline Bar/club & $135(12)$ & $19(7)$ & $103(14)$ & $0.53(0.33$ to 0.85$)$ \\
\hline Street & $526(48)$ & $85(32)$ & $416(55)$ & 0.59 (0.49 to 0.71$)$ \\
\hline Indoor public place & $33(3)$ & $7(3)$ & $22(3)$ & $0.91(0.39$ to 2.11$)$ \\
\hline Public park/open spaces & $78(7)$ & $14(5)$ & $62(8)$ & $0.65(0.37$ to 1.14$)$ \\
\hline School/workplace & $63(6)$ & $15(6)$ & $47(6)$ & $0.92(0.52$ to 1.61$)$ \\
\hline Transport & $35(3)$ & $7(3)$ & $23(3)$ & 0.87 (0.37 to 2.01$)$ \\
\hline Total (missing $n=122$ ) & $1088(100)$ & $266(100)$ & $763(100)$ & - \\
\hline \multicolumn{5}{|l|}{ Relation of victim to assailant } \\
\hline Known (partner/ex-partner, family, friend/acquaintance) & $229(21)$ & $128(49)$ & $88(11)$ & 4.34 (3.45 to 5.48$)$ \\
\hline Stranger & $566(52)$ & $82(32)$ & $458(59)$ & $0.54(0.44$ to 0.65$)$ \\
\hline Unknown & $270(25)$ & $39(15)$ & $208(27)$ & $0.56(0.41$ to 0.77$)$ \\
\hline Work client/customer & $31(3)$ & $10(4)$ & $20(3)$ & $1.49(0.71$ to 3.15$)$ \\
\hline Total (missing $n=114$ ) & $1096(100)$ & $259(100)$ & $774(100)$ & - \\
\hline
\end{tabular}


matches that previously known with a greater risk reported among men, lower socioeconomic groups and younger age groups. ${ }^{1} 13 \quad 14$ Similar to previously described joint working initiatives, ongoing collaborations exist between the hospital and the local Community Safety Partnership to plan prevention strategies for overall reduction of violence in the community; hospital ED data have been used by the local police as part of these initiatives outside the hospital.

However, the specific focus of this paper was to understand whether the ED data can be used for hospital-based initiatives to reduce violence-related crimes in the community. The notable contribution of domestic violence to assaults attending our ED led us to implement an intervention to screen patients for domestic violence in key services within the Trust and to then signpost them to local organisations for support. The study also reflects that the hospital was a point of contact with patients affected by assaults and it offers an opportunistic and safe environment for initiatives such as screening for domestic violence. With women being more likely to be victims of assault at home and to know their assailant, there was a specific focus on hospital clinics providing services to women. The screening intervention and signposting patients was, therefore, initiated in specific clinics including community gynaecology, maternity services and sexual health clinic and is now being rolled out across the Trust.

The study also has limitations. While the survey was aimed at including all patients presenting to the ED with assaults, it is inevitable that the more severely injured and those under a stronger influence of alcohol were unable to participate in the survey. Although the survey achieved a $74 \%$ response rate, it is possible that assaults, particularly related to sensitive issues like domestic violence, were under-reported. The number of patients who were unable to participate in the survey was not systematically recorded during the survey. We were, therefore, unable to identify a reliable denominator to assess response rates to the survey. Missing information on more severe injuries would also have resulted in an underestimation of the severity of assaults reported in this study. The initiative used a paper-based data collection system, which may have also contributed to the incompleteness of the data and technical difficulties in linkage with routine ED data. Furthermore, we were unable to fully explore the contribution of alcohol consumption to assaults. A proxy measure available for alcohol-related assaults was whether the victim consumed alcohol; information on whether the assailant consumed alcohol was not available.

It is known from previous studies that assaults, particularly domestic violence, are under-reported to agencies such as the police. ${ }^{7-9}$ Hospitals, therefore, can provide excellent opportunities as a safe environment for targeted interventions to address public health issues such as assaults. We have shown that hospital data can be used to inform and implement initiatives to address public health issues such as assaults in the local population. Understanding specific determinants of assaults can be used to implement brief interventions in specific areas such as domestic violence to maximise the opportunity of contact with patients in hospital.

Acknowledgements The authors are grateful to the Royal Free Emergency Department reception staff for their help with data collection, to the victims of assault who completed the questionnaire, and to the Public Health Team at NHS Camden and Community Safety Partnership for initiating the project at the Royal Free Hospital.

Contributors SER, AB and AJR developed the original idea of this paper. SER carried out the analysis and wrote the first draft. All authors contributed to the interpretation of the results and preparation of the manuscript. All authors contributed to interpretation of data and the final version of the manuscript, and all are guarantors.

Funding No specific funding was received for this study. SER is funded by a UK MRC Fellowship.

\section{Competing interests None.}

Patient consent Use of routinely collected ED data with ethics committee approval.

Ethics approval Ethical approval for data analysis and publication was obtained from the local research ethics committee (reference 12/SC/0377).

Provenance and peer review Not commissioned; externally peer reviewed.

\section{REFERENCES}

1 Office for National Statistics. Focus on: Violent Crime and Sexual Offences, 2011/ 12. Statistical Bulletin; 2013.

2 Department of Health. Towards healthier, fairer and safer communities-connecting people to prevent violence: a Framework for Violence and Abuse Prevention. 2008.

3 Shepherd JP, Bellis MA, Hughes K. Alcohol and Violence. Faculty of Public Health, 2005.

4 Boyle AA, Snelling K, White L, et al. External validation of the Cardiff model of information sharing to reduce community violence: natural experiment. Emerg Med J 2012;59:909-10.

5 Curtis $F$, Jonathan $S$, lain $B$, et al. Effectiveness of anonymised information sharing and use in health service, police, and local government partnership for preventing violence related injury: experimental study and time series analysis. BMJ 2011;342: d3313.

6 Quigg Z, Hughes K, Bellis MA. Data sharing for prevention: a case study in the development of a comprehensive emergency department injury surveillance system and its use in preventing violence and alcohol-related harms. Inj Prev 2012;18:315-20.

7 Boyle A, Kirkbride J, Jones P. Record linkage of domestic assault victims between an emergency department and the police. J Epidemiol Community Health 2005;59:909-10.

8 Faergemann C, Lauritsen JM, Brink 0, et al. The epidemiology of repeat contacts with an Emergency Department or an Institute of Forensic Medicine due to violent victimization in a Danish urban population. J Forensic Leg Med 2007;14:333-9.

9 Sutherland I, Sivarajasingam V, Shepherd JP. Recording of community violence by medical and police services. Inj Prev 2002;8:246-7.

10 Department of Health. Information Sharing to Tackle Violence: Guidance for Community Safety Partnerships on engaging with the NHS. 2012.

11 Boyle A, Jonathan S, Sheehan D. Guideline for information sharing to reduce community violence. London: The College of Emergency Medicine, 2012.

12 Warburton AL, Shepherd JP. Tackling alcohol related violence in city centres: effect of emergency medicine and police intervention. Emerg Med J 2006;23:12-7.

13 Howe A, Crilly M. Deprivation and violence in the community: a perspective from a UK Accident and Emergency Department. Injury 2001;32:349-51.

14 Sivarajasingam V, Morgan P, Matthews $K$, et al. Trends in violence in England and Wales 2000-2004: An accident and emergency perspective. Injury 2009;40:820-5. 


\title{
EM]
}

\section{Determinants of assault-related violence in the community: potential for public health interventions in hospitals}

\author{
S E Ramsay, A Bartley and A J Rodger \\ Emerg Med J published online August 16, 2013 \\ doi: 10.1136/emermed-2013-202935
}

Updated information and services can be found at:

http://emj.bmj.com/content/early/2013/08/16/emermed-2013-202935.full.html

References This article cites 8 articles, 4 of which can be accessed free at: http://emj.bmj.com/content/early/2013/08/16/emermed-2013-202935.full.html\#ref-list-1

Open Access This is an Open Access article distributed in accordance with the terms of the Creative Commons Attribution (CC BY 3.0) license, which permits others to distribute, remix, adapt and build upon this work, for commercial use, provided the original work is properly cited. See: http://creativecommons.org/licenses/by/3.0/

$\mathbf{P}<\mathbf{P} \quad$ Published online August 16, 2013 in advance of the print journal.

Email alerting service
Receive free email alerts when new articles cite this article. Sign up in the box at the top right corner of the online article.

Advance online articles have been peer reviewed, accepted for publication, edited and typeset, but have not not yet appeared in the paper journal. Advance online articles are citable and establish publication priority; they are indexed by PubMed from initial publication. Citations to Advance online articles must include the digital object identifier (DOIs) and date of initial publication.

To request permissions go to:

http://group.bmj.com/group/rights-licensing/permissions

To order reprints go to:

http://journals.bmj.com/cgi/reprintform

To subscribe to BMJ go to:

http://group.bmj.com/subscribe/ 
Topic Articles on similar topics can be found in the following collections Collections

Child abuse (36 articles)

Abuse (child, partner, elder) (25 articles)

Domestic violence (14 articles)

Violence (14 articles)

Violence against women (14 articles)

\section{Notes}

Advance online articles have been peer reviewed, accepted for publication, edited and typeset, but have not not yet appeared in the paper journal. Advance online articles are citable and establish publication priority; they are indexed by PubMed from initial publication. Citations to Advance online articles must include the digital object identifier (DOIs) and date of initial publication.

To request permissions go to:

http://group.bmj.com/group/rights-licensing/permissions

To order reprints go to:

http://journals.bmj.com/cgi/reprintform

To subscribe to BMJ go to:

http://group.bmj.com/subscribe/ 